\title{
The Scope of Climate Assemblies: Lessons from the Climate Assembly UK
}

\author{
Stephen Elstub $^{1, * \mathbb{C}}$, Jayne Carrick ${ }^{1}$, David M. Farrell ${ }^{2} \mathbb{D}$ and Patricia Mockler ${ }^{3}$ \\ 1 Department of Politics, School of Geography, Politics and Sociology, Newcastle University, \\ Newcastle NE1 7RU, UK; Jayne.Carrick2@newcastle.ac.uk \\ 2 School of Politics and International Relations, University College Dublin, D04 V1W8 Dublin, Ireland; \\ david.farrell@ucd.ie \\ 3 Department of Political Studies, Queens University, Kingston, ON K7L 3N6, Canada; p.mockler@queensu.ca \\ * Correspondence: stephen.elstub@newcastle.ac.uk
}

Citation: Elstub, S.; Carrick, J.; Farrell, D.M.; Mockler, P. The Scope of Climate Assemblies: Lessons from the Climate Assembly UK. Sustainability 2021, 13, 11272. https:/ / doi.org/10.3390/su132011272

Academic Editor: Sergiu Gherghina

Received: 29 July 2021

Accepted: 7 October 2021

Published: 13 October 2021

Publisher's Note: MDPI stays neutral with regard to jurisdictional claims in published maps and institutional affiliations.

Copyright: (c) 2021 by the authors. Licensee MDPI, Basel, Switzerland. This article is an open access article distributed under the terms and conditions of the Creative Commons Attribution (CC BY) license (https:/ / creativecommons.org/licenses/by/ $4.0 /)$.

\begin{abstract}
In recent times we have seen a spate of climate assemblies across Europe as the climate emergency gains increasing prominence in the political agenda and as the citizens' assembly approach to public engagement gains popularity. However, there has been little empirical research on how the scope of citizens' assemblies affects the internal logic of the assembly process and its impacts on external policy actors. This is a significant oversight given the power of agenda setting. It is also of particular importance for climate assemblies given the exceptional scale and complexity of climate change, as well as the need for co-ordination across all policy areas and types of governance to address it. In this paper, we start to address this gap through an in-depth case analysis of the Climate Assembly UK. We adopt a mixed methods approach, combining surveys of the assembly members and witnesses, interviews with the assembly members, organisers, MPs, parliamentary staff, and government civil servants, and non-participant observation of the process. We find that attempts to adapt the assembly's scope to the scale of the climate change issue compromised assembly member learning, the co-ordination of the resulting recommendations, assembly member endorsement of the recommendations, and the extent of their impact on parliament and government. We argue that more democratization in setting the agenda could help combat these issues.
\end{abstract}

Keywords: citizens' assemblies; climate change; decarbonization; agenda setting; deliberative democracy; mini-publics; environmental politics

\section{Introduction}

The citizens' assembly approach to public engagement has gained popularity following perceived successes in Ireland [1]. Given the increasing prominence of the climate emergency in the political agenda, especially on the approach to COP26, citizens' assemblies have been used increasingly to address climate change issues. We have seen a spate of such 'climate assemblies' across Europe.

Citizens' assemblies are a type of mini-public. They recruit a representative, or diverse, selection of members of the public through various forms of civic lottery (stratified random selection), provide the participants with information on the topic to be considered, and facilitate their discussion to promote deliberative norms and enable the participants to address the assembly remit [2]. Moreover, they are thought to be more equipped at cultivating long-term thinking than traditional liberal democratic institutions $[3,4]$ and a better way of engaging the public with the climate change issue than other methods [5].

However, there has been little empirical research on the impacts of the scope of citizens' assemblies on their design and influence on policy. This is a notable oversight given the power and unequal nature of agenda setting [6]. The agenda is of particular importance in the case of climate assemblies, given the significant scale and complexity of climate change and the need for co-ordination across all policy areas and levels and types of governance to 
address it [3,7]. Perhaps reflecting the relative recency of the 'democratic wave' (barely a decade old [8]), the research on this topic to date has been predominantly theoretical and focused on who sets an assembly's agenda and how the assembly is managed, rather than on the consequences and impacts of an assembly's scope.

In this paper, we address this gap through an in-depth case analysis of the Climate Assembly UK (CAUK). It was commissioned by six select committees from the House of Commons, and given the remit of addressing the question: 'How should the UK meet its target of net zero greenhouse gas emissions by 2050?' The UK is an interesting case generally, not least given that a large number of climate assemblies have been run at various levels of governance across the country, probably more than in most countries [9]. Furthermore, CAUK is an important case specifically as it was the first nationwide citizens' assembly in the UK and, indeed, the first national climate assembly in the UK. Moreover, it split assembly members into thematic groups as a measure to compensate for the broad scope of the assembly. Whilst an unusual approach for citizens' assemblies generally, this is becoming increasingly common for climate assemblies.

We adopt a mixed methods approach combining surveys of the assembly members and witnesses, interviews with the assembly members and organisers, MPs and parliamentary staff, and government civil servants, as well as non-participant observation of the process. We find that the attempts to adapt the assembly scope to the scale of the climate change issue compromised assembly member learning, the co-ordination of the resulting recommendations, assembly member endorsement of the recommendations and the extent that they impacted on parliament and government. Whilst the need for trade-offs between the breadth and depth of the scope of climate assemblies can never be eliminated, especially given inevitable constraints with respect to time and budget, we argue for a two-step process for setting the agenda for a citizens' assembly. Step one requires the commissioning authority to set a broad remit for the assembly, to ensure they receive recommendations on a policy area that they are interested in and looking for public guidance on. Step two enables the assembly members themselves to determine the specific remit of the assembly, once they have received some initial information.

The paper proceeds as follows. In Section 2, we review the literature on climate and citizens' assemblies on agenda setting and scope. In Section 3 we justify our case study approach and case selection and give an overview of Climate Assembly UK. Section 4 provides details of our mixed methods approach. In Section 5 we present our results, and in Section 6 discuss our analysis with respect to the scope of CAUK and its consequences. We conclude in Section 7 with some pointers for further research in this area. Our findings have relevance for climate assembly design in particular, but also for citizens' assemblies, mini-publics, and public engagement in climate change policy more broadly.

\section{Citizens' Assemblies and Their Agendas}

Citizens' assemblies can be defined as 'carefully designed forums where a representative subset of the wider population come together to engage in open, inclusive, informed, and consequential discussions on one or more issues' [10]. They are a type of mini-public which means that random and stratified sampling is used to ensure the assembly participants are representative of the population, or at least diverse, with respect to key demographics and often attitudes on the issue. Participants are often renumerated for their time and travel, accommodation and childcare etc. are usually provided to lower the barriers to participation. The participants are then given relevant information on the issue from a range of experts and advocates. They engage with this information, and their own views, through facilitated discussions aimed at promoting deliberative norms such as inclusion, respect, and reason-giving. They result in a set of policy recommendations on the topic. In comparison to other mini-publics, citizens' assemblies tend to have a 'larger' number of participants (typically 100 [8]), a 'longer' duration, and be connected, in some tangible way, to established political institutions, (see [2] for an overview of the design 
features of the different types). Climate assemblies are a citizens' assembly that addresses the issue of climate change.

This section provides a review of existing research on the agenda and scope of citizens' assemblies. We find that the literature in this area, while acknowledging the importance of the agenda, is limited, predominantly theoretical, focused primarily on agency, and, moreover, does not cover climate assemblies. We argue that the absence of empirical research on the scope of an assembly, and its consequences for assembly design and its potential to impact policy, is a significant oversight in citizens' assembly research in general but especially in relation to climate assemblies. This is due to the unique nature of the scope of the climate change issue. We therefore identify a need for more empirical research in this area. First, we start with an overview of existing research on climate assemblies.

Climate Assembly UK is part of a growing wave of climate assemblies globally. With renewed interest in the urgency of the climate crisis, governments at all levels have used the mini-public model to involve citizens in proposing recommendations to minimize the impacts of the crisis [11]. This is important because the climate governance debate has been dominated by scientists, interest groups, and politicians, with the public rendered 'spectators' [12]. In the context of disengagement from traditional avenues of participation, deliberative forms of civic engagement have become increasingly attractive tools for policymakers [13]. Citizens' assemblies offer a unique approach to responding to the issue of climate change. Smith [4] and Fisher [3] argue that citizens' assemblies allow for the consideration of complex, longer-term issues such as the climate crisis. This is distinct from typical policy-making by elected officials who tend to focus on short-term goals, in response to electoral incentives, public opinion and media coverage, and also promote climate delay discourses [14]. There is empirical evidence that deliberation [15,16] in citizens' assemblies [17] can promote concern for future generations.

This may be because the citizens' assembly model allows for in-depth learning and respectful discussion among participants and thus is well-suited for addressing complex and polarizing issues such as climate change [18,19], as it provides a format in which the public are receptive to climate science [12]. Drawing on evidence from an Australian minipublic, Niemeyer [20] (p. 448) argues that 'deliberative democracy ... has the potential to transform the public response to climate change'. Climate activists like Extinction Rebellion seem to agree and have also called for climate assemblies to inject long-term thinking into the political system.

Previous research has explored the impact participating in a climate assembly has on the participants, including the implications for fostering public support for policies to address climate change [11,12,21]. For example, Devaney et al. [5] (p. 144) argue that the citizens' assembly method can be a powerful tool for 'engaging and communicating with the public more deeply on the climate crisis.' Howarth et al. [19] similarly argue that climate assemblies are a useful tool that can help to 'build a social mandate' for addressing the climate crisis. Research has also considered the external factors of climate assemblies such as the impact they have on government policy [11] and the reasons why they are instigated [22]. However, a key gap in the existing research is how far the scope of the climate assembly agenda may influence these internal and external dynamics.

The process by which issues are selected for discussion is structured by the 'value choices and the political power of the players' involved [23] (p. 35). This political power includes the ability to determine which issues are important and how they are framed, which exacerbates existing inequalities [6] as it is the stage of the process where the 'mobilisation of bias is at its highest' [24] (p. 84). There is also a path dependency here, as the scope of a citizens' assembly will determine many of the design features and the interest of policy-makers and the public in the process and its outcomes [25]. Therefore, the process of issue selection in a mini-public is 'of fundamental importance' [26] (p. 343).

However, much of the research on the agenda of mini-publics has been theoretical [24-28]. The empirical studies that have covered the agenda have focused on the agenda setting agents. This work has found that agenda setting is inherently political and 
typically reflects the priorities of the commissioning body [29-34]. For Richardson [27] (p. 184), this means that mini-publics with pre-determined agendas 'will tell us little of value about the popular will' as policy makers will remain uninformed about the issues that matter to the public most. For Böker and Elstub [28], it inhibits the potential of mini-publics to contribute to the more critical and emancipatory aspirations of deliberative democracy as a normative theory.

On the other end of the spectrum 'open' and 'bottom-up' agenda setting processes provide opportunities for participants in a mini-public to determine the topic to be discussed; examples of these include the 'We the Citizens' pilot in 2011 [35] and Austrian Wisdom Councils [36]. Recent data indicate that open agendas were employed more frequently since 2015, compared with previous years studied [37]. There are limitations of this approach to agenda setting too. Firstly, there is a reduced opportunity for the assembly to impact on policy if it is on a topic that is not of interest to policy-makers. Secondly, as mini-publics recruit representative samples of the public, they may not have the knowledge of particular issues to be able to set their own agenda $[2,13]$.

Other methods allow for citizen control of the agenda but do not limit this authority to members of the mini-public. For example, the so-called 'Ostbelgien model' provides an opportunity for citizens to create the agenda; in this case, a permanent Citizens' Council is given the power to commission a citizens' assembly on a topic of the Council's choice [33]. In a similar manner, the issues considered during the G1000 were drawn from proposals by the public through an online consultation [34].

Another aspect of agenda-setting within a deliberative setting that there has been research on is the level of influence afforded to citizens in structuring the formal agenda after an issue has been selected. Lang [32] adds an important consideration to our discussion of agenda-setting. Her study examines the parallel processes of informal and formal agenda setting in the BCCA and serves as a reminder of the role of power and the significant consequences for the deliberative experience of both formal and informal agenda-setting.

However, again the research here primarily focuses on agency. Smith's [13] (p. 89) work on democratic innovations argues that in a typical mini-public, citizens are asked to consider an issue area that has been chosen in advance following a 'format that has been established without their involvement'. However, more recent scholarship suggests variations on this front. For example, in the French Citizens' Convention for Climate, the members had input into the selection of expert witnesses [38], as has been the practice in the Irish processes [30]. Choosing the speakers within a mini-public can function as a form of agenda-setting, as each individual speaker brings their own perspective and expertise. There is potential for expert witnesses' own opinions to influence the outcome of an assembly [13,39]. Expert selection is usually a task performed by the organisers or their stewarding board [40,41]. A further variant is offered by the case of the Irish Citizens' Assembly, which included a 'steering group' of members who were charged with providing feedback and guidance on meeting plans [30].

Consequently, while citizens' assembly research has flagged the importance of the agenda, it has primarily focused on agenda setting agents. There is only limited research on the consequences of scope of the mini-public on other factors and most of it is theoretical. For example, Dryzek [42] (p. 28) argues that mini-publics 'require that well-defined boundaries can be drawn around issues.' For others, the scope of the agenda for a citizens' assembly is of particular importance, because if it is not suitably refined and narrow it is likely to result in poor quality deliberation [13] (pp. 89, 97) [2] (p. 182).

Agenda scope is an issue of particular relevance for climate assemblies given its significant breadth and complexity, which means that it affects every aspect of modern life and therefore all policy and governance areas [3,7]. To date, climate assemblies have focused predominantly on mitigation, rather than adaptation, but, nevertheless, they also tend to have very broad remits [43]. The assembly scope has consequences for how time in the assembly can be used. The British Columbia Citizens' assembly met for 26 days [39], and yet its focus on electoral reform, while significant in scope, pales in comparison to the 
scope and complexity of climate change. Therefore, we know very little about how the remit and scope of climate assemblies can be appropriately designed to be proportionate to the time available. Assembly design is crucial to enable the time available to assembly members to be used most effectively to do justice to the significance and breadth of the issue, while enabling the members to become informed about key elements of the issue relevant to the assembly remit. In turn, there is a dearth of research on how the scope of climate assemblies affects their impact on policy. Moreover, existing research focuses on agency and which actors set the agenda of assemblies but gives insufficient attention to the nature and consequences of these choices for the assembly. Shaw et al. [43] have started to fill this gap with an overview of the remits of several European climate assemblies, but do not provide new empirical data. Therefore, more empirical research on this topic is required. It is these significant gaps that the paper seeks to address through a case analysis of the Climate Assembly UK. We next provide an overview of our case and the rationale for its selection.

\section{Empirical Case: Climate Assembly UK}

To address our research questions of how assembly scope affects both the internal design of assemblies and policy impact, we adopt a case study approach. Case study research allows for the gathering of intensive and contextual data that will help us understand the internal dynamics of the assembly [44]. The rich contextual data that case study research unveils can enhance understanding of how an institution, in our case a climate assembly, relates to a variety of actors, across a range of locations within a political system [45]. Moreover, case studies are useful for building theory through the generation of hypotheses [46], which is helpful given the lack of research on citizens' assembly scope to date as highlighted in the previous section.

Climate Assembly UK (CAUK) was the first nationwide citizens' assembly in the UK, and the first national climate assembly in the UK. It was also one of the first nationallevel citizens' assemblies focused specifically on the climate emergency (the 'environment' generally had featured in a number of CAs by then [10] (Figure 2.3), but the particular focus on the climate emergency is a more recent phenomenon), joining a short list that - at that stage-included France (whose climate assembly somewhat overlapped in timing with CAUK) [38] and Ireland (whose 2016-2018 citizens' assembly included climate change as one of five topics to consider) [47]. Despite the limited research on climate assemblies to date, which might lead us to classify CAUK as a 'revelatory case', we see it as a 'common case' [46] due to the relatively large number of climate assemblies in Europe that there are now [48], and also because CAUK has many similar design features to these other cases (e.g., the use of thematic groups to create a division of labour amongst the assembly members), thereby making it a typical and representative case.

CAUK comprised of 108 randomly selected members of the public from across the UK. It met over a period of six weekends from late January to mid-May 2020. This was a longer period than had been anticipated (four weekends) due to the COVID-19 pandemic which prompted the assembly to move online. It was commissioned by six select committees from the House of Commons, which asked it to consider the question: 'How should the UK meet its target of net zero greenhouse gas emissions by 2050?' This remit followed the government legislation that committed the UK to reaching this identical target. Parliament commissioned a public participation organisation (Involve) to organise CAUK and provided them with a list of topic areas, agenda-setting questions, and areas to prioritise which collectively covered the six select committees' interests on climate change and the net zero target.

In particular, the parliamentary committees wanted CAUK to give sufficient attention to three key topics: 'how we travel', 'in the home', and 'what we buy and land use, food and farming'. Furthermore, the parliamentary committees had specified certain topics that should be deprioritised in the case of time constraints, on the basis of the committees' interests. These included freight transport, green investment, direct industrial emissions 
and consumption emissions (i.e., emissions from processes that take place outside of the UK but are 'imported' via goods and services).

To cover these topics in the time allotted, during most of weekend 2 and the whole of weekend 3, the assembly members (AMs) were split randomly into three different topic groups meeting in separate rooms, each tasked with considering a topic. The members of each group were selected randomly and stratified (based on the same criteria used at the recruitment stage of the assembly), so that the membership of each group remained as representative and diverse as possible. AMs were not allowed to change group. AMs were informed of the product of these separate topic deliberations in short presentations and those more interested were advised to watch the livestreams. The division of AMs into topic groups impacted on CAUK's recommendations; some recommendations that AMs later voted on were the product of deliberations that they had not been party to, and some recommendations were voted on by the topic group only (accounting for a third of the AMs). As we discuss below, this was to cause some disquiet among several AMs, and it also affected how some parliamentary and government observers treated the import of the recommendations.

In common with the design of citizens' assemblies generally, the AMs were a randomly selected, stratified sample of UK citizens with respect to key demographics and attitudes to climate change and rural and urban dwelling. There was a mixture of small group and plenary sessions throughout the assembly and the AMs were supported by a team of external experts, advocates, and facilitators. A team of 'expert leads', who had expertise on different aspects of climate change, were convened to oversee the process. These were selected by the organisers, based on advice received from trusted experts in the sector, and were approved by Parliament at the end of the tender process. The expert leads were advised by a 12-member academic panel and an advisory panel consisting of 19 experts from private, public, and charity sectors, all related to climate change. Steps were taken to ensure that there was balance on the advisory panel with respect to demographics, stakeholder groups and political backgrounds. The members of both panels were initially proposed by climate change specialists in the Parliamentary Office of Science and Technology (POST) and agreed in consultation with the expert leads. With guidance from the academic panel, the expert leads drafted content for CAUK, which was then issued to the advisory panel for comment, including who was invited to present (expert witnesses) and what they should be asked to cover. They were also asked to comment on documents between meetings, as were POST.

A brief overview of the agenda for each weekend of CAUK is provided in Table 1. Like most mini-publics, CAUK broadly adhered to a format that started with learning about the topic, followed by deliberation and decision making. As detailed in Table 1, the learning phase was predominately undertaken during weekend 1 and 2 . This was followed by deliberation and decision-making. We now proceed to give an overview of the research methods used to analyse this case study.

Table 1. Overview of the Climate Assembly UK (CAUK) agenda.

\begin{tabular}{cccc}
\hline Weekend & Format & Purpose & Activities \\
\hline 1 & In-person & Introduce the topic & $\begin{array}{c}\text { Presentations on climate change and ethical and practical questions } \\
\text { about the path to net zero. The AMs decided on the principles and } \\
\text { values they want the Government to use to guide the path to net zero. }\end{array}$ \\
\hline 3 & $\begin{array}{c}\text { In-person and in } \\
\text { topic groups }\end{array}$ & $\begin{array}{c}\text { Provide } \\
\text { information }\end{array}$ & $\begin{array}{c}\text { AMs were split into three different topic groups. They heard } \\
\text { presentations on their topic followed by question-and-answer sessions. }\end{array}$ \\
& $\begin{array}{c}\text { In-person and in } \\
\text { topic groups }\end{array}$ & $\begin{array}{c}\text { AMs given summaries of other topic groups, then discussed and voted } \\
\text { on key considerations for decision-makers. } \\
\text { Deliberation and } \\
\text { decision-making }\end{array}$ & $\begin{array}{c}\text { AMs reviewed and discussed what they had learnt about their own } \\
\text { topics in weekend 2, and then voted on considerations for Government } \\
\text { and Parliament about their topic. AMs were presented with a range of } \\
\text { 'future scenarios' and 'policy options' for their topic which they } \\
\text { discussed and voted on. }\end{array}$ \\
\hline
\end{tabular}


Table 1. Cont.

\begin{tabular}{cccc}
\hline Weekend & Format & Purpose & Activities \\
\hline $\begin{array}{c}4 \mathrm{a}, 4 \mathrm{~b} \text { and } \\
4 \mathrm{c}\end{array}$ & Online & $\begin{array}{c}\text { Provide } \\
\text { information, } \\
\text { deliberation, and } \\
\text { decision-making }\end{array}$ & $\begin{array}{c}\text { In plenary, all AMs heard presentations on new topics. Each topic } \\
\text { information session was followed by Q\&A, deliberation, and voting. } \\
\text { On the last day of the assembly, the AMs discussed, proposed and } \\
\text { voted on 'final recommendations' for the report. }\end{array}$ \\
\hline
\end{tabular}

\section{Materials and Methods}

This paper adopts a mixed methods approach, combining qualitative and quantitative data collected from surveys of the AMs and speakers, interviews with the AMs, CAUK organisers, parliamentarians, and government, as well as non-participant observation of sessions. Each data source is summarised in Table 2 and explained below.

Surveys of participants are a standard and widely used approach to researching minipublics [2]. As detailed in Table 2, we surveyed AMs at the start and end of each CAUK weekend, as well as the expert witnesses around four months after the close of the assembly. While the surveys informed us of what the assembly members thought about the process, as well as how they perceived it had affected their knowledge and views of climate change and decarbonisation, they provided limited insight into the reasons why the AMs thought this. To overcome this limitation, we supplemented the surveys with qualitative methods.

Qualitative methods such as interviews are particularly suited to answer research questions related to how democratic innovations emerge and the effects they have on participants and public policies [49], both of which strongly relate to our research questions for CAUK (how assembly scope affects both the internal design of assemblies and policy impact). Therefore, we generated qualitative data from interviews as well as non-participant observation.

Non-participant research approaches are useful for linking findings with processes in mini-public research, especially when they are supplemented with interviews [49], as we do in our study. It can change how researchers perceive assembly members, organisers, facilitators, experts, how these groups interact, and the process design that influences this interaction, as observations uncover taken-for-granted aspects of the assembly process [50]. In this study, a member of the research team attended and observed each of CAUK's inperson weekends and listened to audio recordings of the online sessions. They also attended the online report launch and the subsequent online stakeholder briefings. Researchers' observations were recorded in a field diary, structured around the research questions. These were then coded and analysed according to the research questions and to capture emerging themes.

The use of mixed methods in social sciences is well established and is valued for facilitating triangulation [51]. As described above, quantitative and qualitative methods used alone have their limitations, but by combining them these are compensated for, enabling meta-inferences to be made that draw on numerous data sources [52] (p. 512). This is considered the best approach for researching democratic innovations like citizens ${ }^{\prime}$ assemblies [52] where we seek to understand the assembly as a whole, particular aspects of it, and its broader context. In this study we used a mixed method approach to assess the data from different perspectives and explore the complex research questions including what happened within the assembly, especially with respect to the scope of the remit provided, and how these affected perceptions of other political actors towards the assembly.

There are risks and limitations in using mixed methods research. Conducting multiple strands of research can be complicated [53]. Combining data from mixed methods into integrated analysis can also be difficult [54]. In this study, we managed this by dividing the collection and analysis of the different types of data between the four authors, who worked closely together to help harmonize the different data sources. As described above, each method was selected to address specific aspects of the research questions; the purpose of the analysis from each data source was established from the outset to facilitate integration. 
Table 2. Summary of the methods of data collection.

\begin{tabular}{|c|c|c|c|c|c|}
\hline Source & Participants & When & Delivery & Format & Analysis \\
\hline \multirow[t]{2}{*}{ Surveys } & $\begin{array}{l}\text { Assembly Members: } 99 \text { of } \\
108 \text { AMs who consented * }\end{array}$ & $\begin{array}{l}\text { Start and end of each } \\
\text { weekend }\end{array}$ & $\begin{array}{l}\text { In-person in weekends } 1,2 \\
\text { and } 3 \text {, and digitally on the } \\
\text { online weekends }\end{array}$ & $\begin{array}{l}\text { Open and closed questions covering: knowledge } \\
\text { of and attitudes to climate change; experiences at } \\
\text { CAUK; political attitudes and interests; and } \\
\text { activities between the weekends. }\end{array}$ & $\begin{array}{l}\text { Quantitative data analysed to track how } \\
\text { knowledge, opinions, attitudes, abilities and } \\
\text { experiences evolve throughout the process. } \\
\text { Analysis, completed in SPSS, included } \\
\text { descriptive statistics, correlations, } t \text {-tests, and } \\
\text { multi-variate regression. }\end{array}$ \\
\hline & $\begin{array}{l}\text { Expert witnesses: } 21 \text { of } 48 \\
\text { who consented }\end{array}$ & September 2020 & Digital survey & $\begin{array}{l}\text { Open and closed questions on motivations and } \\
\text { expectations of taking part, and experiences of } \\
\text { presenting and engaging with AMs. }\end{array}$ & $\begin{array}{l}\text { Quantitative data analysis, completed in SPSS } \\
\text { included descriptive statistics, correlations } \\
\text { and } t \text {-tests. }\end{array}$ \\
\hline \multirow{2}{*}{ Interviews } & $\begin{array}{l}\text { Assembly members: } 28 \text { AMs } \\
* * \text { from } 75 \text { who consented }\end{array}$ & June and July 2020 & Online & $\begin{array}{l}\text { Semi-structured: AMs were asked about their } \\
\text { motivation for participating, their perspectives on } \\
\text { the experience of participating, and views and } \\
\text { engagement on climate change and politics. }\end{array}$ & \multirow{2}{*}{$\begin{array}{l}\text { The interviews were recorded, transcribed, } \\
\text { and then coded according to the research } \\
\text { questions, but also to capture emerging } \\
\text { themes by using a staged hybrid approach to } \\
\text { thematic analysis }[55,56] \text {. }\end{array}$} \\
\hline & $\begin{array}{l}16 \text { MPs and Parliamentary } \\
\text { staff } * * *\end{array}$ & $\begin{array}{l}\text { September-November } \\
2020\end{array}$ & Online & $\begin{array}{l}\text { Semi-structured: they were asked about how and } \\
\text { why CAUK was established; their contact with the } \\
\text { process; thoughts on the process and the } \\
\text { recommendations; and future plans to act on the } \\
\text { assembly recommendations. }\end{array}$ & \\
\hline $\begin{array}{l}\text { Non-Participant } \\
\text { Observation }\end{array}$ & $\mathrm{N} / \mathrm{A}$ & Each CAUK weekend & $\begin{array}{l}\text { In person attendance on } \\
\text { weekends } 1,2 \text { and } 3 \text {, and } \\
\text { from recordings of the online } \\
\text { sessions }\end{array}$ & $\begin{array}{l}\text { Researchers recorded their observations in a field } \\
\text { diary, structured around the research questions. }\end{array}$ & $\begin{array}{l}\text { Observations were coded and analysed } \\
\text { according to the research questions and to } \\
\text { capture emerging themes. }\end{array}$ \\
\hline
\end{tabular}

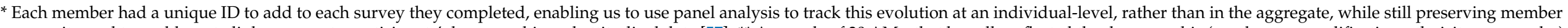

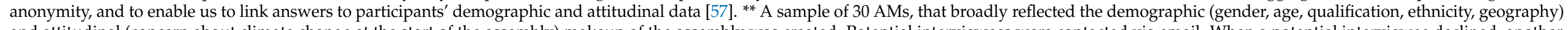

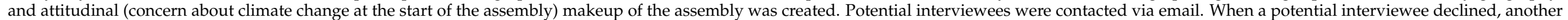

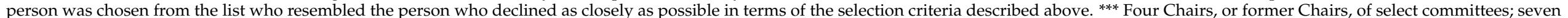

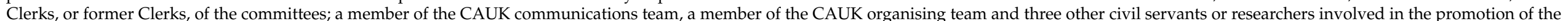
CAUK report and recommendations within government. 
In the following section we report our key findings derived from the application of these mixed methods to CAUK.

\section{Results}

Our analysis of the scope of CAUK, and how this affected internal aspects of the assembly and its uptake in policy, is divided into four inter-related sections. First, we consider the relationship between time and issue scope. Second, we analyse how the assembly scope affected information provision and learning. Third, the consequences of splitting the assembly into topic groups are investigated, which was one of the main measures introduced to enable the broad scope to be managed in the available time. Fourth, we present the two-step agenda-setting process which includes the democratisation of assemblies as a potential solution to the problems we identify in our analysis.

\subsection{Time}

As discussed previously, the assembly members met for a total of six weekends. Three meetings were conducted in person, followed by three that took place online. Decisions about the length of CAUK were determined by budget constraints and, crucially, the significant costs associated with member accommodation and travel that are unavoidable for in-person meetings.

Our examination of the assembly indicates that the short time frame allotted for consideration of such a complex and broad issue was insufficient (by comparison, the issue of electoral system change was considered by two citizens' assemblies that were allotted six weekends for learning alone, followed by six additional weekends for deliberation [39]). This combination had an impact on the AMs' experience. Many noted a desire to have more time for each of their assigned tasks: learning, deliberating, and voting on recommendations. One consequence of the desire to ensure AMs were well-briefed despite the short time frame was that each meeting day was long and full, with some tasks even being completed over an evening meal. One member commented, 'it was a lot of information to take in and it was very, very, very tiring... I was exhausted because you had to take it all in and understand it and try and remember what they said ... It was hard going'. This was also observed by the researchers, who noted that the long days had an impact on levels of AM engagement. This is especially important given that the membership was diverse and thus included participants who were not accustomed to participating in long meetings. Overall, many AMs suggested the process was too short: 'Ideally the assembly should have been more than four weekends to discuss further options and more proposals.'

Expert witnesses expressed a similar concern about the amount of time provided for their presentations, given the breadth and technical complexity of the ideas they were asked to cover and the wide range of prior knowledge of the topic among the audience. Some worried about the volume of information that they were expected to present within the time constraints. One witness noted that 'it would be challenging to meet the brief' due to the complexity of the topic and the time available. Others agreed: one stated that they 'expected it would be challenging to make [their] presentation simple enough', and another worried about 'explaining my area clearly within the time available.' Many members noted the value of engaging with the presenters at their tables and that this allowed members to ask more detailed questions; both expert witnesses and members indicated that they would have preferred these sessions to be longer.

In sum, the evidence points us to the conclusion that there was a mismatch between the scope of the agenda of the assembly and the time available for AMs to address it in a sufficiently meaningful way.

\subsection{Information and Evidence Provision and Learning}

Our AM survey data suggests that the extensive methods of information provision were, overall, effective. Most AMs understood the information and were able to use it to inform their decisions; the majority of AMs also agreed that they had learnt a lot 
from the information provided during weekends 1, 2 and 3, as shown in Figure 1. In addition, in our interviews of the expert witnesses it was noted that members asked relevant questions throughout the assembly (something that was also observed by the research team), suggesting a level of comfort with the material.

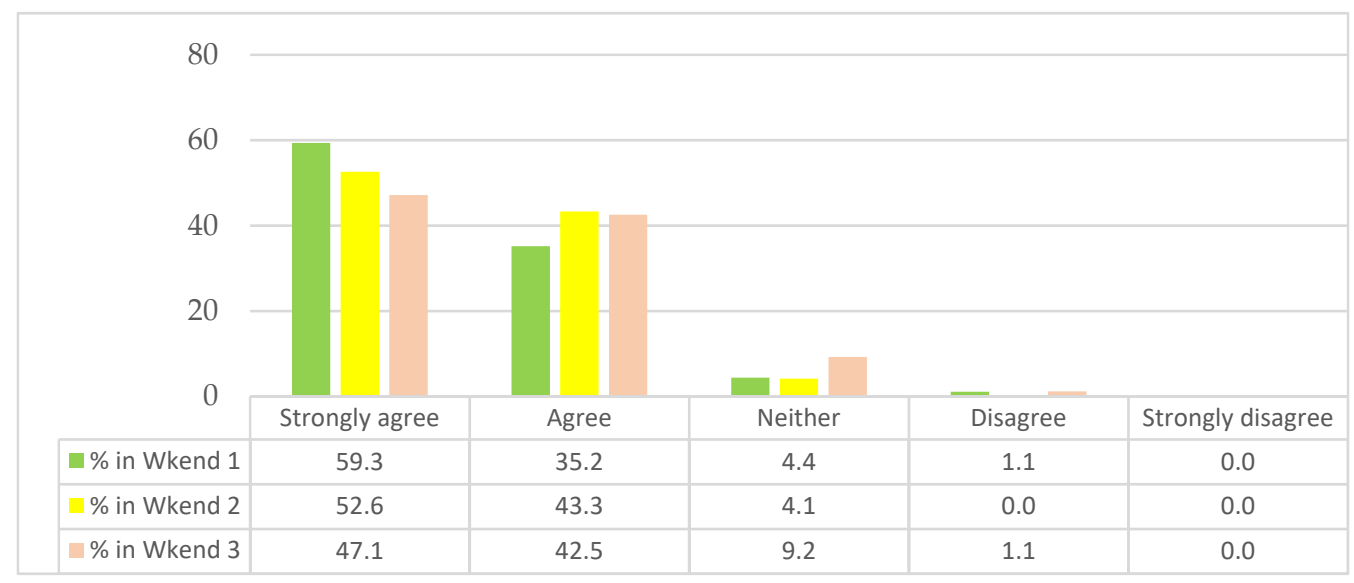

Figure 1. Extent the assembly members (AMs) felt they had learnt a lot from the speakers.

However, our analysis further indicates that the extent the AMs agreed that they had learnt a lot decreased over the course of the assembly. On a scale of 1 (strongly agree) to 5 (strongly disagree), the mean response was 1.47 after weekend 1, 1.52 after weekend 2, and 1.64 after weekend 3 . The results of $t$-tests reveal there is a statistically significant mean difference between the responses given after weekend 1 and 3 , indicating that learning decreased as the process progressed, with the most amount of learning occurring in the early stages of CAUK.

Moreover, the volume of information, pace of delivery, and use of jargon sometimes overwhelmed some of the AMs and left them feeling that some topics had not been explained in the necessary level of detail or in a manner that was accessible to the diverse membership in the room. In an interview one AM reflected that they got 'the feeling that a lot of people were ending the day very confused ... don't forget, we came from nothing ... very little information ... and we are suddenly supposed to sort of take it and make a decision.' Another AM noted that they, 'found it quite difficult to take it all in and understand it and then quickly generate questions'. In weekend 3, some AMs said that they had not been given enough time to receive and digest all the information from the first two weekends. While it is obvious from the many methods of information provision that a concerted effort was made to ensure members were able to learn in a supportive environment, it appears that, given the broad scope of the assembly, the time allotted did not allow all members to fully assimilate the material before voting on the assembly's recommendations.

In addition, despite the large volume of information provided, the researchers' fieldnotes recorded that some AMs identified what they considered to be important gaps in the content covered during the assembly. For example, some asked why specific issues were not covered, such as freight transport and tidal and wave technology, and queried the depth of some topics. These concerns were echoed by the expert witnesses. In response to an open question in the survey, one expert witness encapsulated the issues arising from time constraints and gaps in information: 'I felt the whole thing was rather compressed. Some sectors were not covered ... Ideally, the members should have more time and ability to call for additional speakers.' The researchers observed that, when questioned about gaps in information, the lead facilitators often blamed time constraints for limiting evidence provision.

It therefore seems apparent that the scope of the assembly created issues for the provision of information and opportunities for members learning. 


\subsection{Thematic Groups}

The CAUK designers seemed aware of the tensions between the broad scope of the assembly and the time available to address it. One of the main attempts to address this was to split the assembly into three thematic groups, as explained by one of the organisers: 'So, it's a big topic, isn't it? ... it was the first time we'd split into groups like that at a national assembly which, I think reflects the size of the topic.'

A significant consequence of this decision was that many of the recommendations were only endorsed by a segment of the AMs. Even though there was the briefing to ensure that all AMs were aware of what was being discussed by the other groups, it was decided, nonetheless, that for some of the decisions, AMs should only vote on recommendations from their own topic group because the other AMs had not had enough opportunity to make a sufficiently informed vote. As explained by one of the CAUK organisers: 'we just felt that the people who looked at it in detail ... would potentially have gone on quite a journey of learning and changing their opinions and learning from each other and then if you put it back to a vote of everybody who hadn't had the same information without having a chance to bring them up to speed on the evidence. What were you gaining from that if you're looking for an informed output?'

This use of separate topic groups had implications both for what AMs thought of the process, and also for the reception of the CAUK's recommendations. We can deal with each in turn. Some AMs raised issues with the final recommendations, noting that they were not given adequate opportunity to participate in the production of recommendations by topic groups to which they were not assigned. Some felt that the process of reporting the work of the topic groups was not sufficient for members to provide an informed vote. One participant raised the issue of the recommendations being presented to the public as reflecting his perspective, when he had not participated in the deliberation and drafting of recommendations of the two other issue areas: ' ... when it says the Climate Assembly supports this decision, I've not had any information about what to do in the home. I've not had any information to do with the farming or anything like that. Even though we got that information afterwards, it was always the stuff that had already been agreed rather than the information that led to that decision'. In the open text comments on the AM survey, complaints about being split into topic groups were frequent, such as 'Not being involved in the other two discussions' and 'Missing the other topics.' This suggests that the measures to integrate the work of the thematic groups were considered insufficient.

The results of the AM survey suggest that most of the AMs agreed with the principles and decisions made in weekends 1 and 3 (see Figure 2). On a scale of 1-5, where 1 is very much agree/strongly agree and 5 is not at all agree/strongly disagree, the extent AMs agreed with proposed principles and decisions decreased on average between weekend 1 and weekend 3; the mean answer was 2.07 for decisions made in weekend 1, and 2.13 for weekend 3 . However, a $t$-test shows that there is no statistically significant mean difference between the survey answers. This indicates that the difference between the extent the AMs said that they agreed with proposed principles and decisions made in weekend 1 and after they were split into thematic groups in weekend 3 is not significant.

Figure 3 illustrates the degree to which the AMs felt they had influenced the decisions made in weekend 1 , after they had been split into thematic groups in weekend 3 , and online in weekends $4 \mathrm{a}-\mathrm{c}$. Using the same five-point scale as above, the extent the AMs thought that they influenced the decisions decreased, on average, over the course of the assembly; the mean answer was 2.12 for decisions made in weekend 1, 3.01 for weekend 3, and 2.90 for weekends $4 \mathrm{a}-\mathrm{c}$. The results of $t$-tests indicate the mean difference between the answers given after weekend 1 and 3 , as well as the difference between weekends 1 and $4 a-c$, were statistically significant. This indicates that the extent the AMs thought they influenced the decisions reduced between weekend 1 and being split into thematic groups, and weekend 1 and the online weekends. 


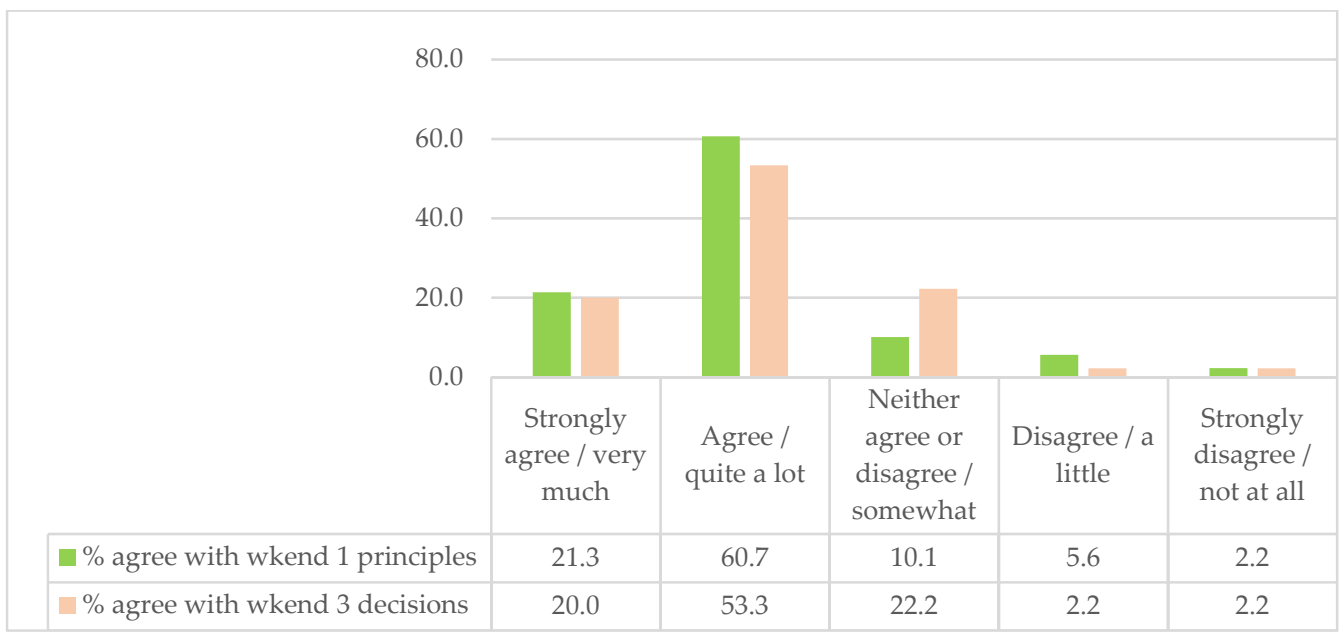

Figure 2. Extent assembly members (AMs) agreed with proposed principles and decisions made in Climate Assembly UK (CAUK).

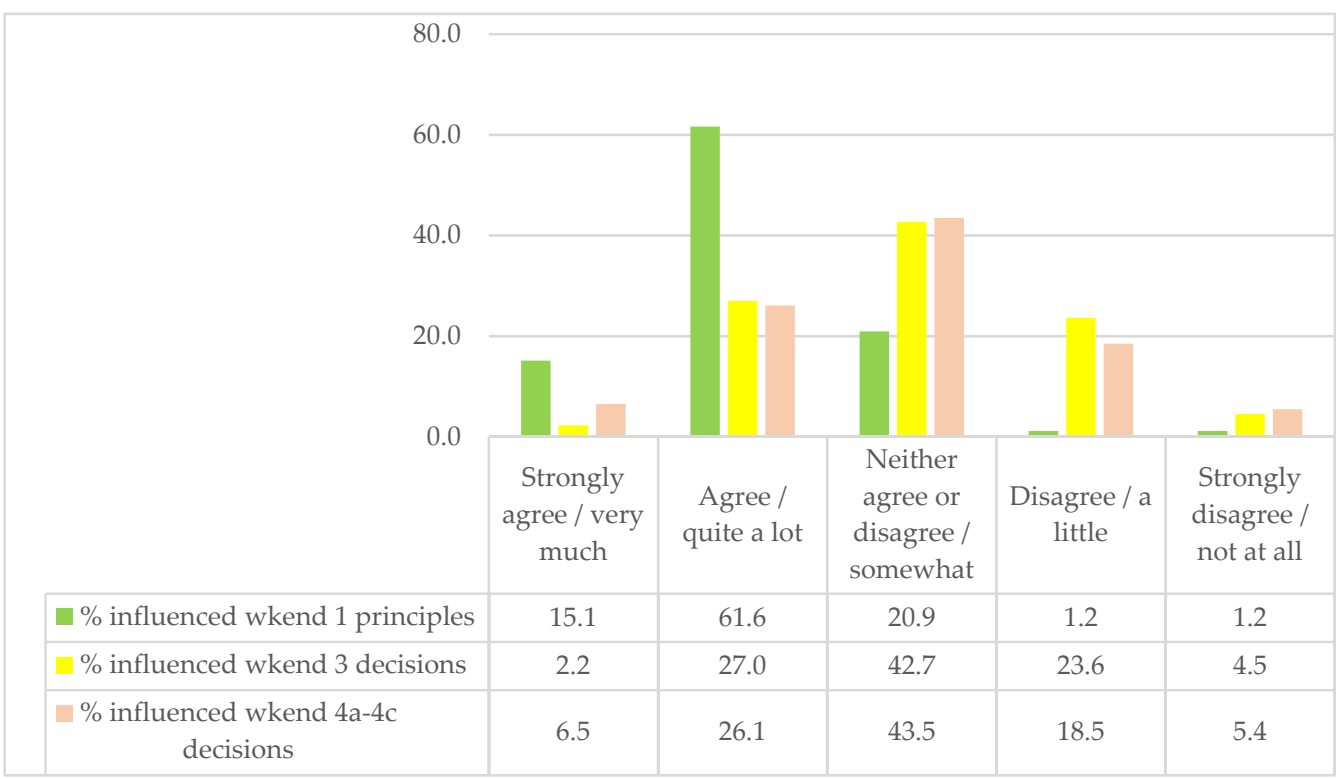

Figure 3. Extent assembly members (AMs) thought they influenced the decisions made in Climate Assembly UK (CAUK).

We might be tempted to conclude that in each case these are minority views, and that most AMs agreed with the decisions and thought that they had influenced them to some degree. However, the whole logic behind a citizens' assembly is that they should be highly inclusive spaces. The fact that the extent AMs felt they influenced decisions before and after they were split into the thematic groups changed so much is cause for concern. Indeed, the researchers' observational fieldnotes also noted that access to sufficient information was limited by splitting the AMs into three topic groups. Furthermore, it compromised the ability of the AMs to co-ordinate their recommendations. For example, decisions were being made about 'how we travel' whilst unaware of what decisions were being made on 'what we buy' and vice versa, as if these are unrelated topics that do not need to be harmonised in order to decarbonise effectively.

Concerns were also expressed in interviews with several of the civil servants who were tasked with briefing government ministers on the CAUK report. For one this was 'probably the most problematic thing. Because ... you have to tell a minister that only actually 36 or 37 people voted on a certain thing.... it's hard to ... convince them of the 
weight of it'. This concern was shared by another, who noted: 'Government might not do something because 17 out of 30 people said they voted for it.' Clearly, policy makers want to know what all the participants think about an issue and not just a segment of it. Indeed, this is the distinct advantage and purpose of a citizens' assembly having representative samples. Addressing the broad scope of the assembly further led to the production of a large number of recommendations (50 in total). This makes holding both Parliament and Government accountable in responding to all of the recommendations more challenging.

Dividing the assembly into thematic groups did have the positive consequence that some AMs got a more in-depth understanding of a particular topic, but this is at the expense of learning across the topics, being able to co-ordinate the recommendations, and enabling all AMs to endorse all the recommendations, which in turn can lead to politicians feeling less impetus to implement them. We now turn to consider some solutions to these perennial issues for mini-publics.

\subsection{Democratising Climate Assemblies}

The AMs were given some opportunities to shape the course of CAUK. In weekend 3, AMs got to discuss if there was anything else on the topic of decarbonisation that they would like to tell Government and Parliament. There was also a board where members could log issues that they think should be considered but that were not on the agenda. The COVID-19 recovery and the path to net zero topics that were covered in the assembly came from AM suggestions. This indicates that AMs can make important agenda-setting decisions. Measures like this should be integrated throughout the assembly process and used instead of top-down design methods. Our evidence indicates that AMs would welcome such opportunities. For example, some AMs noted that they were confused when they returned for week 3; specifically, they reported that they were being asked to vote on items while unclear on their origin. Some 'scenarios' were provided by the expert leads for the AMs to vote on: e.g., for 'what we buy', AMs were presented with three possible futures, offering different emphases on efficiency, repairing and sharing, and using less stuff. Some AMs were unhappy that the expert leads had proposed the 'Future Scenarios' rather than the AMs. One AM said:

'I lost my way completely between week 2 and week 3 . When we came back to week 3 we were going down paths that I had not consciously or subconsciously or to my awareness of anybody I spoke to about it had actually structured where the paths in week 3 had come from. We arrived at week 3 and were suddenly presented with alternatives that I personally didn't buy into because I hadn't been party to how we got there. I was having a little bit of difficulty if you like accepting that I was going to roll with it from then on .... To the point, where on the first vote that we did... I refused to participate because I didn't own them, I didn't own what was being asked of me.'

The fact that they felt unable to vote is quite damming, but assembly democratisation could combat these types of instances. We now move to discuss the implications of our findings, and the democratization of assembly agendas further.

\section{Discussion}

Our empirical study supports theoretical work on the fundamental importance [26] of agenda-setting in mini-publics. It does indeed determine many aspects of design of the assembly [25]. Problems with issue scope are not an unusual phenomenon in mini-publics. There are inevitable trade-offs that have to be made between depth and scope of evidence given the realities of budget limits in constraining the time allotted to a given mini-public. However, these problems are more acute in climate assemblies given the breadth and complexity of the issue $[3,4,7]$.

There are potential solutions to some of the issues raised here. An obvious one is to give more time and resources to the deliberative process to allow sufficient space to give the subject-matter the full consideration it warrants. CAUK was run on a relatively tight budget $(£ 560,000)$ and kept to a limited time period (originally of just four weekends, 
that was extended by a further two due to the need to move online during the COVID-19 pandemic). Contrast this with the French climate assembly that had a budget of $€ 5.4 \mathrm{~m}$ and was given a longer time period (10 weekends) (although, despite this the French process also chose to use thematic groups $[38,58])$.

In CAUK, as with many previous cases [29-34], the determination of the focus of each topic group was done in a top-down manner; the parliamentary committees set the agenda and insisted on all dimensions being given equal treatment. To allay a lot of the concerns of assembly members about having more input into the process, thought should be given to introducing more democratic procedures into the assembly agenda and design. A better approach would have been to enable the AMs to refine the scope of the assembly themselves. While the AMs would not have been in a position to make these important agenda-setting decisions at the very start of the assembly $[2,13]$, there is no reason why they could not be empowered to make these choices once they had become more informed about climate change and decarbonisation after the first weekend. Figure 1 suggests that AMs are sufficiently equipped to decide which aspects of decarbonisation interested them and mattered to them most reasonably early in the process. They would effectively reign in the scope of the assembly themselves by setting their own priorities.

This two-stage agenda setting process has several advantages, but comes with risks too. Firstly, the commissioning public authority (in the case of CAUK, the six select committees from the UK's House of Commons) gets to determine the broad agenda of the assembly. As opposed to a purely bottom-up mini-public agenda-setting processes, this means they would not be receiving recommendations on a policy area on which they had little interest in, no plans to legislate on, or had already made up their mind about $[2,13]$; all of which would negate being influenced by the assembly. Secondly, it would enable the AMs to determine the more specific remit that they will address; thereby affording policy makers greater insight into the priorities of an informed and representative portion of the public [27], as well as enabling the scope of the assembly to be reined in and avoiding some of the tensions, outlined above, the broad scope of CAUK caused. Thirdly, if AMs did decide that a split into thematic groups was appropriate to address the issue, it could have less impact on policy take-up as it would have been a decision taken by all the AMs themselves. Of course, the danger that the AMs take the remit of the assembly too far from the commissioning authority's interests and, in turn, reduces the potential for policy impact remains [59].

There are other risks to this two-stage agenda-setting process too. The AMs may not sufficiently refine the scope of the broad agenda given by the commissioning authority, and therefore fail to address it in the time available. Refining the agenda democratically may also prove very time consuming, compromising the capacity of the AMs to provide meaningful recommendations. We believe these challenges can be overcome through effective assembly design and facilitation. Lessons should also be learnt from other cases $[5,9,11,21,22,38,58-60]$.

For example, in the Irish assemblies, they established an AMs' reference group, [30], in which representatives of the AMs provided suggestions on the itinerary of assembly meetings, the proposed expert witnesses, and the time given to areas to be discussed. The concern with this approach is that it undermines the equality of the AMs, but it is time efficient. Alternatively, a regional climate assembly from the UK was set a broad remit, but organizers enabled the participants to determine which aspects of climate change mitigation they wanted to focus on in the available time [60]. Moreover, we recommend more experimentation of new measures to democratise citizens' assemblies given the relatively small number of cases that have introduced these democratic measures.

\section{Conclusions}

In citizens' assemblies, trade-offs between the scope of the agenda, depth and breadth of learning, assembly duration and budgets are inevitable. Due to the unique nature of the issue, these tensions are more acute in climate assemblies, where there is a trend to 
divide the assembly into topic groups to enable more of the vast issue to be covered [58]. Designers of climate assemblies should be aware that there are negative consequences to this approach. Our mixed method study of CAUK, that drew on surveys, interviews, and non-participant observation, found that dividing the AMs into different topic groups compromised the breadth of learning for many AMs and undermined their endorsement of recommendations from topic groups which they did not participate in. In turn, it has also hindered the potential of CAUK to influence UK climate policy as policy makers may feel less pressure to adopt recommendations coming from only a sample of the assembly, and thereby adding to the challenges for climate assemblies to influence policy [11,59].

A climate assembly cannot consider the whole issue of climate change, given it applies to every policy area, type of governance and aspect of life [3,4,7]; the scope has to be reined in somehow. We suggest a two-step approach to this. The commissioning authority should provide the broad remit of the assembly. This would help ensure the recommendations that they receive are aligned with their policy priorities and are on issues on which policymakers do not already have a determined agenda. However, the assembly should be democratised to enable the AMs themselves to decide their own priorities and to have a say on the types of information they need to address them. Our evidence indicates that AMs would be well-equipped to do this quite early in the process after being provided background information on climate change. Inspiration from mini-publics that have used democratising techniques should be drawn on $[30,60]$, but more experimentation is also required.

This is, of course, just one case study, and due to the absence of research in this area our study is exploratory and therefore more empirical evidence on this vital topic is clearly required. Given the number of climate assemblies occurring across Europe at present $[5,9,11,21,22,38,58-60]$, many of which are implementing topic groups within the assembly, comparative analysis would therefore be welcome.

Nevertheless, given research on the scope of citizens' assemblies has been limited, focused on agency, largely normative, and has not specifically focused on climate assemblies, our case study analysis starts to fill an important gap. The remit of an assembly not only affects assembly design, but also how it is perceived by other political actors in the system.

Author Contributions: Conceptualization, S.E. and D.M.F.; Data curation, S.E., J.C., D.M.F. and P.M.; Formal analysis, S.E., J.C., D.M.F. and P.M.; Funding acquisition, S.E.; Investigation, S.E., J.C., D.M.F. and P.M.; Methodology, S.E., J.C., D.M.F. and P.M.; Project administration, S.E. and J.C.; Resources, S.E.; Supervision, S.E.; Writing—original draft, S.E., J.C., D.M.F. and P.M.; Writing—review \& editing, S.E., J.C., D.M.F. and P.M. All authors have read and agreed to the published version of the manuscript.

Funding: UKRI QR Strategic Priorities Grant, UK Parliament, and Social Science and Humanities Research Council of Canada.

Institutional Review Board Statement: Ethical approval was provided by the University of Newcastle.

Informed Consent Statement: All research participants gave their written informed consent for inclusion before they participated in the study.

Data Availability Statement: The data presented in this study are available on request from the corresponding author. The data are not publicly available due to privacy.

Conflicts of Interest: The authors declare no conflict of interest.

\section{References}

1. Farrell, D.; Suiter, J. Reimagining Democracy: Lessons in Deliberative Democracy from the Irish Front Line; Cornell University Press: Ithaca, NY, USA, 2019.

2. Elstub, S. Mini-publics: Issues and Cases. In Deliberative Democracy: Issues and Cases; Elstub, S., McLaverty, P., Eds.; Edinburgh University Press: Edinburgh, UK, 2014; pp. 166-188.

3. Fischer, F. Climate Crisis and the Democratic Prospect; Oxford University Press: Oxford, UK, 2017.

4. Smith, G. Can Democracy Safeguard the Future? Polity Press: Cambridge, UK, 2021. 
5. Devaney, L.; Torney, D.; Brereton, P.; Coleman, M. Ireland's Citizens' Assembly on Climate Change: Lessons for Deliberative Public Engagement and Communication. Environ. Commun. 2020, 14, 141-146. [CrossRef]

6. Bachrach, P.; Baratz, M.S. Two Faces of Power. Am. Political Sci. Rev. 1962, 56, 947-952. [CrossRef]

7. Dryzek, J.S.; Norgaard, R.B.; Schlosberg, D. (Eds.) The Oxford Handbook of Climate Change and Society; Oxford University Press: Oxford, UK, 2011.

8. OECD. Innovative Citizen Participation and New Democratic Institutions: Catching the Deliberative Wave; OECD Publishing: Paris, France, 2020.

9. Citizens' Assembly Tracker. Available online: https:/ / www.involve.org.uk/citizens-assembly-tracker (accessed on 28 July 2021 ).

10. Curato, N.; Farrell, D.M.; Geißel, B.; Grönlund, K.; Mockler, P.; Pilet, J.-B.; Renwick, A.; Rose, J.; Setälä, M.; Suiter, J. Deliberative Mini-Publics: Core Design Features; Bristol University Press: Bristol, UK, 2021.

11. Sandover, R.; Moseley, A.; Devine-Wright, P. Contrasting Views of Citizens' Assemblies: Stakeholder Perceptions of Public Deliberation on Climate Change. Politics Gov. 2021, 9, 76-86. [CrossRef]

12. Ghimire, R.; Anbar, N.; Chetri, N.B. The Impact of Public Deliberation on Climate Change Opinions Among U.S. Citizens. Front. Political Sci. 2021, 3, 13. [CrossRef]

13. Smith, G. Democratic Innovations: Designing Institutions for Citizen Participation; Cambridge University Press: Cambridge, UK, 2009.

14. Lamb, W.F.; Mattioli, G.; Levi, S.J.; Roberts, T.; Capstick, S.; Creutzig, F.; Minx, J.C.; Müller-Hansen, F.; Culhane, T.; Steinberger, J.K. Discourses of climate delay. Glob. Sustain. 2020, 3, 1-5. [CrossRef]

15. Hara, K.; Yoshioka, R.; Kuroda, M.; Kurimoto, S.; Saijo, T. Reconciling intergenerational conflicts with imaginary future generations: Evidence from a participatory deliberation practice in a municipality in Japan. Sustain. Sci. 2019, 14, 1605-1619. [CrossRef]

16. MacKenzie, M.K.; Caluwaerts, D. Paying for the future: Deliberation and support for climate action policies. J. Environ. Policy Plan. 2021, 23, 317-331. [CrossRef]

17. Kulha, K.; Leino, M.; Setälä, M.; Jäske, M.; Himmelroos, S. For the Sake of the Future: Can Democratic Deliberation Help Thinking and Caring about Future Generations? Sustainability 2021, 13, 5487. [CrossRef]

18. Dryzek, J.S.; Stevenson, H. Democratizing Global Climate Governance; Cambridge University Press: Cambridge, UK, 2014.

19. Howarth, C.; Bryant, P.; Corner, A.; Fankhauser, S.; Gouldson, A.; Whitmarsh, L.; Willis, R. Building a Social Mandate for Climate Action: Lessons from COVID-19. Environ. Resour. Econ. 2020, 76, 1107-1115. [CrossRef] [PubMed]

20. Niemeyer, S. Democracy and climate change: What can deliberative democracy contribute? Aust. J. Politics Hist. 2013, 59, 429-448. [CrossRef]

21. Muradova, L.; Walker, H.; Colli, F. Climate change communication and public engagement in interpersonal deliberative settings: Evidence from the Irish citizens' assembly. Clim. Policy 2020, 20, 1322-1335. [CrossRef]

22. Oross, D.; Mátyás, E.; Gherghina, S. Sustainability and Politics: Explaining the Emergence of the 2020 Budapest Climate Assembly. Sustainability 2021, 13, 6100. [CrossRef]

23. Dietz, T.; Stern, P. Public Participation in Environmental Assessment and Decision Making; National Academies Press: Washington DC, USA, 2008.

24. Smith, G. Taking Deliberation Seriously: Institutional Design and Green Politics. Environ. Political 2001, 10, 72-93. [CrossRef]

25. Goodin, R.E. Sequencing deliberative moments. Acta Politica 2005, 40, 182-196. [CrossRef]

26. Fung, A. Survey Article: Recipes for Public Spheres: Eight Institutional Design Choices and Their Consequences. J. Political Philos. 2003, 11, 338-367. [CrossRef]

27. Richardson, H.S. Public opinion and popular will. In Deliberative Democracy in Practice; Kahane, D., Weinstock, D., Leydet, D., Williams, M., Eds.; University of British Columbia Press: Vancouver, BC, USA, 2010; pp. 177-193.

28. Böker, M.; Elstub, S. The possibility of critical mini-publics: Realpolitik and normative cycles in democratic theory. Representation 2015, 51, 125-144. [CrossRef]

29. Elstub, S. Linking Micro Deliberative Democracy and Decision-Making: Trade-Offs Between Theory and Practice in A Partisan Citizen Forum. Representation 2010, 46, 309-324. [CrossRef]

30. Farrell, D.; Suiter, J.; Harris, C. 'Systematizing' constitutional deliberation: The 2016-18 citizens' assembly in Ireland. Ir. Political Stud. 2019, 34, 113-123. [CrossRef]

31. Johnson, G.F. Democratic Illusion: Deliberative Democracy in Canadian Public Policy; University of Toronto Press: Toronto, ON, Canada, 2015.

32. Lang, A. Agenda-setting in Deliberative Forums: Expert Influence and Citizen Autonomy in in the British Columbia Citizens' Assembly. In Designing Deliberative Democracy; Warren, M.E., Pearse, H., Eds.; The British Columbia Citizens' Assembly, Cambridge University Press: Cambridge, UK, 2008.

33. Niessen, C.; Reuchamps, M. Designing a Permanent Deliberative Dialogue: The Ostbelgien Model in Belguim; Centre for Deliberative Democracy \& Global Governance: Canberra, Australia, 2019.

34. Caluwaerts, D.; Reuchamps, M. The Legitimacy of Citizen-Led Deliberative Democracy: The G1000 in Belgium; Routledge, Taylor and Francis Group: London, UK; New York, NY, USA, 2018.

35. We the Citizens. We the Citizens_Speak up for Ireland: Participatory Democracy in Action; We the Citizens: Dublin, Ireland, 2011.

36. Asenbaum, H. Facilitating Inclusion: Austrian Wisdom Councils as Democratic Innovation between Consensus and Diversity. J. Deliberative Democr. 2016, 12. [CrossRef] 
37. Paulis, E.; Pilet, J.-B.; Panel, S.; Vittori, D.; Close, C. The POLITICIZE dataset: An inventory of deliberative mini-publics (DMPs) in Europe. Eur. Political Sci. 2020, 20, 521-542. [CrossRef]

38. Convention Citoyenne Pour le Climat: What Can We Learn from the French Citizens' Assembly on Climate Change? Available online: https:/ / www.involve.org.uk/resources/blog/opinion/convention-citoyenne-pour-le-climat-what-can-we-learn-frenchcitizens (accessed on 28 July 2021).

39. Fournier, P.; van der Kolk, H.; Carty, R.K.; Blais, A.; Rose, J. When Citizens Decide; Oxford University Press: Oxford, UK, 2011.

40. Arnold, T.; Farrell, D.; Suiter, J. Lessons from a Hybrid Sortition Chamber: The 2012-2014 Irish Constitutional Convention. In Legislature by Lot: Transformative Designs for Deliberative Governance; Gastil, J., Wright, E.O., Eds.; Verso Books: London, UK, 2019; pp. 121-122.

41. Roberts, J.; Lightbody, R.; Low, R.; Elstub, S. Experts and evidence in deliberation: Scrutinising the role of witnesses and evidence in mini-publics, a case study. Policy Sci. 2020, 53, 3-32. [CrossRef]

42. Dryzek, J.S. Foundations and Frontiers of Deliberative Governance; Oxford University Press: Oxford, UK, 2010.

43. Shaw, C.; Wang, S.; Latter, B. How Does the Framing of Climate Change Affect the Conclusions Reached in Climate Asemblies. Available online: https:/ / climateoutreach.org/reports/knoca-climate-assemblies-framing/ (accessed on 8 October 2021).

44. Gomm, R.; Hammersley, M.; Foster, P. (Eds.) Case Study Method: Key Issues, Key Texts; Sage: London, UK, 2004.

45. Ercan, S.; Hendriks, C.; Boswell, J. Studying Public Deliberation After the Systemic Turn: The Crucial Role for Interpretive Research. Policy Politics 2017, 45, 195-212. [CrossRef]

46. Yin, R. Case Study Research Design and Methods; Sage: Thousand Oaks, CA, USA, 2014.

47. Devaney, L.; Brereton, P.; Torney, D.; Coleman, M.; Boussalis, C.; Coan, T.G. Environmental literacy and deliberative democracy: A content analysis of written submissions to the Irish Citizens' Assembly on climate change. Clim. Chang. 2020, 162, 1965-1984. [CrossRef]

48. Knowledge Network on Climate Assemblies. Available online: https:/ / knoca.eu/previous-climate-assemblies/ (accessed on 28 July 2021).

49. Tailpin, J. Qualitative Approaches to Democratic Innovations. In The Handbook of Democratic Innovation and Governance; Elstub, S., Escobar, O., Eds.; Edward Elgar: Cheltenham, UK, 2019; pp. 486-500.

50. Laurier, E. Participant and Non-Participant Observation. In Key Methods in Geography; Clifford, N., Cope, M., Gillespie, T., French, S., Eds.; Sage: London, UK, 2016.

51. Brannen, J. Mixed Methods Research: A Discussion Paper (NCRM/005), ESRC National Centre for Research Methods. Available online: https:/ / www.researchgate.net/publication/251776164_Mixed_Methods_Research_A_Discussion_Paper (accessed on 8 October 2021).

52. Escobar, O.; Thompson, A. Mixed methods research in democratic innovation. In The Handbook of Democratic Innovation and Governance; Elstub, S., Escobar, O., Eds.; Edward Elgar: Cheltenham, UK, 2019; pp. 501-514.

53. Teddlie, C.; Tashakkori, A. A general typology of research designs featuring mixed methods. Res. Sch. 2006, 13, 12-28.

54. Bryman, A. Barriers to Integrating Quantitative and Qualitative Research. J. Mix. Methods Res. 2007, 1, 8-22. [CrossRef]

55. Fereday, J.; Muir-Cochrane, E. Demonstrating Rigor Using Thematic Analysis: A Hybrid Approach of Inductive and Deductive Coding and Theme Development. Int. J. Qual. Methods 2006, 5, 80-92. [CrossRef]

56. Swain, J. A Hybrid Approach to Thematic Analysis in Qualitative Research: Using a Practical Example; Sage Research Methods: London, UK, 2018.

57. Finkel, S.E. Causal Analysis with Panel Data; Sage: London, UK, 1995.

58. Cherry, C.E.; Capstick, S.; Demski, C.; Mellier, C.; Stone, L.; Verfuerth, C. Citizens' Climate Assemblies: Understanding Public Deliberation for Climate Policy; The Centre for Climate Change and Social Transformations: Cardiff, UK, 2021.

59. Wells, R.; Howarth, C.; Brand-Correa, L.I. Are citizen juries and assemblies on climate change driving democratic climate policymaking? An exploration of two case studies in the UK. Clim. Chang. 2021, 168, 1-22. [CrossRef]

60. Shared Future, The North of Tyne Citizens' Assembly on Climate Change. 2021. Available online: https://www.northoftyne-ca. gov.uk/projects / citizens-assembly-on-climate-change/\#: \{\}:text=In\%20May \%202019\%20upon \%20his $\% 20$ election $\% 20$ as $\% 20$ the, do $\% 20$ in $\% 20$ the $\% 20$ region $\% 20$ to $\% 20$ tackle $\% 20$ climate $\% 20$ change (accessed on 8 October 2021). 